\title{
Notas
}

\section{ANTONIO TABUCCHI}

\section{Mirar los monstruos}

Este año un periódico español, Cambio 16, cuyo suplemento cultural cumple 10 años, ha tenido la idea de llamar a un sinnúmero de escritores para que escriban un texto sobre la memoria. El tema del suplemento es "Recordar" y se invita a cada uno de los escritores a recordar alguna cosa o a escribir algo en torno al recuerdo. Los escritores no poseen mejor memoria que las demás personas, por supuesto: tienen, como todos, una memoria que puede ser engañosa, fugaz, defectuosa. Pero esto no es el punto importante. Lo importante es que ellos producen memoria. La literatura es antes que nada memoria, la larga memoria de todos nosotros.

Creo que el hombre no ha sentido jamás la necesidad de una memoria larga como en este fin de milenio, en el que los medios tecnológicos y la difusión televisiva imponen su memoria: una memoria corta y niveladora en la que el recuerdo del ayer es aplastado pór el recuerdo del hoy y por la que a un genocidio en una parte del mundo le corresponden algunos segundos de imagen inmediatamente antes o inmediatamente después de los segundos de imagen que le corresponden al gran premio automovilístico de otra parte del mundo.

Muchos son los monstruos que nos rodean. Nuestro mundo está poblado de monstruos enormes, espantosos, amenazadores, fúnebres, mortíferos, exterminadores. En primer lugar el Gran Monstruo, La Bomba, con el que todos nosotros "tendríamos" que convivir. Y los demás monstruos: el hambre, la miseria, la explotación, el fanatismo. $Y$ los seres monstruosos que a menudo acompañan a estos monstruos: los tiranos, los dictadores, los bandidos.

$\mathrm{Y}$ sin embargo, parece como si los hombres ya no fueran capaces de ver estos monstruos. Los miran, pero no los ven. La rapidez y la simul taneidad de la información quitan a los monstruos toda densidad, todo está en el mismo nivel: un nivel inmediato que hay que consumir como 
un fast-food, el nivel de la costumbre, donde ya nada significa nada, donde las distancias se anulan y las diferencias desaparecen.

Las cosas, el significado de las cosas; y lo real, o el significado de lo real, se sustituyen con la imagen de las cosas y con la imagen de lo realuna imagen que convierte lo real imaginario, las cosas imaginarias y que las aleja de nosotros haciéndonos perder todo juicio de valor.

Contra esta memoria corta, yo reivindico la literatura como memoria larga, porque la literatura no es la imagen de las cosas sino las cosas vi vidas dentro de las cosas, es lo real vivido dentro de lo real: y esto es lo verdaderamente real, porque es un real que contiene juicio, sentimiento y pasión, es un real con un sentido. Y poco importa si este real se ha vivido en el pragma, en el alma o en la fantasía: lo que está escrito es lo que un hombre ha vivido dentro de sí, en un determinado momento y en un determinado lugar de esta tierra. $Y$ esta es la memoria de ese momento, una memoria paciente e implacable, porque la literatura es paciente e implacable.

Incluso ha sido posible, en la historia de los hómbres, falsificar la historia. La historia está hecha de teorias y de abstracciones; se presta a reinterpretaciones de última hora. Pero a esos venenosos historiadores de última hora que quisieran hacernos creer que el nazismo ha sido uno de los "normales" momentos de la ferocidad humana, y que en comparación con otros feroces momentos ni siquiera ha sido el peor, yo constesto con la memoria que me han dejado los libros de Primo Levi. $Y$ contesto que rechazo con indignación y con espanto el médir la violencia para con el hombre comparándola con otra violencia. Porque la violencia que un hombre padece, aunque sea uno solo, es absoluta y no se puede comparar con nada - ésta rechaza el relativo y el relativismo, rechaza también la interpretación y el perdón. Que los científicos interpreten y los papas perdonen. Es su deber. La literatura no tiene esa función. Ésta escribe, cuenta. Hace vivir los acontecimientos y por eso no es falsificable.

Como la historia, así los documentos con los que los hombres habi tualmente hacen historia pueden ser falsificados. Cuántas personas, en este último medio siglo, han desaparecido de las fotografias. Una fotografía de un dictador de mi país, un triste personaje que llevó la muer te y la destrucción a Italia y a Europa, lo representa sobre un luminoso pedestal donde con letras está escrito: "Dux". Pero la fotografía original sin embargo lo representaba en medio de matones como él, a los que después el favor de la historia no ha beneficiado. Otro magnífico ejemplo de fotografia falsificada nos lo ha ofrecido Carlos Franqui en un su plemento de Cambio 16, del que antes he hablado y además existe una preciosa novela de Milan Kundera que comienza con una fotografía fal- 
sificada. Lo real visto desde fuera se falsifica con facilidad. Pero la literatura no se puede falsificar. Sólo se puede prohibir.

$Y$ es por lo que hoy reivindico también la literatura como forma de ética: porque sobrepasa las éticas particulares, estatales o fidelistas impuestas por los regímenes políticos, por las religiones o por las normas de comportamiento. En una época en la que las ciencias que detentan el poder de vida y de muerte sobre el planeta, como la física y la química, no son capaces de elaborar una deontología; en esta época nuestra, me pregunto, éen qué ética creer, si no en la memoria que la literatura nos da? Una memoria de lo que hemos sido y de lo que estamos viviendo, de lo que hoy somos. Me doy perfecta cuenta que esta memoria no modifica inmediatamente el presente, que no es inmediatamente vencedora. Pero ésta es larga, obstinada - y quema. Un poeta que ha escrito en mi lengua ha dicho que en este tiempo de oscuridad él se conformaba con tansmitir la luz de una cerilla. Los personajes de mis libros son tal vez hombres inseguros y desorientados; no buscan grandes respuestas, no ofrecen soluciones, sino que se conforman con un tenue resplandor, una pequeña luz: la de ser lo que son, la de pensar lo que piensan, la de vivir ahora y aquí, en este tiempo que nos ha tocado vivir. $Y$ mientras Augusto Pinochet y Juan Pablo II, estrechándose la mano, desaparecen por la esquina del televisor para dejar paso al gran premio de automovilismo, yo enciendo mi cerillita mientras abro un libro de un escritor chileno. Pero a la luz de esa cerilla los monstruos toman cuerpo, su monstruosidad es iluminada por la luz más viva. 